\title{
On the Cultural Communication between Teenagers in China Eastern and Western Regions---Aiming at Promoting the Education of Ethnic Unity and Progress
}

\author{
Lieming Fanga ${ }^{\mathrm{a}}$, Junyi Hou, * \\ Shandong Youth University of Political Science, Jinan, China. \\ afanglieming@126.com, bjunyihou@163.com
}

\begin{abstract}
The education of the ethnic unity and progress is a big issue concerning national unity and identity. It is also a long term task related to the safety and stability of China, which includes the education on nationalities identities and unity, respecting religious belief and folk customs, building harmonious ethnic relations and enhance cultural identity. The activities about teenagers culture communication in the eastern and western regions, such as two-way communication, short-term exchange studying, and expanding the scope of participants in the project, have contributed to strengthening the education of ethnic unity and progress.
\end{abstract}

Keywords: Education of ethnic union and progress; China eastern and western regions; cultural communication among teenagers

\section{Introduction}

The ethnic unity and progress oriented education includes the education on national unity and national identity, respecting the religious beliefs, habits and customs, harmonious ethnic relations, the identity of national culture and so on. "The cause of national unity and progress is an important social project that must be promoted in the new historical conditions". The education of national unity and progress is an issue concerning national unity and the Chinese identity. It is related to the various nationalities of China. It is the state's long-term task that is essential to the stability of the nation.

The national youth is the country's future and the hope of the China. Adolescence is a critical period that the outlook on life and values are formed. Through cultural exchanges in the East and West of teenagers, national unity and progress education could be strengthened.

\section{The Influence of the Culture Communication between Teenagers in the Eastern and Western Regions on Strengthening the Education of National Unity and Progress}

There are 56 nationalities in China, among which the Han nationality is the largest one which accounts for ninety-two percent of the whole population. The other 55 ethnic nationalities are referred as ethnic minorities. The distribution in the eastern and western regions is as follows: the eastern regions are mostly inhabited by Han nationalities while the minorities live in most of the western regions (Southern west areas and Northern west areas). Yunnan province is the province that inhabits the largest number of ethnic minorities.

\subsection{Its Impact on Strengthening National Unity and National Identity Education.}

China is a unified multi-ethnic country. Cultural exchanges of teenagers between the East and West regions deepens the understanding of the various groups, enhances the national affinity and the understanding between people and strengthens the sense of national identity. Cultural communication between the East and the west is beneficial to ethnic unity and national identity education.

\subsection{Its Impact on Education of Religious Beliefs, Customs and Habits.}

In the western region of China,there are various religious and the customs in different regions are different. Each ethnic group has a unique custom in food, clothing, housing, weddings, funerals, festivals, taboos, and most of them have their own national holidays. Through youth cultural exchanges, the majority of young people tend to respect other ethnic group's different habits , customs, religious and beliefs from historical perspective and with respecting and tolerant attitude. Therefore, 
it enhances the unity among the ethnic groups and plays a certain role in the education of respecting the religious beliefs and customs.

\subsection{Its Impact on Education of Harmonious National Relationship.}

Ethnic unity is essential to harmonious society construction and national unity. Ethnic relation is a vital national political and social relation in China. The more national communication, the closer ethnic relations is. The cultural exchange of east and west promotes national association, makes ethnic connection closer, ethnic relations more harmonious. The cultural exchanges among young people between east and west plays an important role in promoting harmonious ethnic relations.

\subsection{Its Impact on Education of National Culture's Identity.}

In the west of China, the long history has bred the splendid culture. Western culture, characterized by regionalism, pluralism and original ecological, is an important component in Chinese culture. The culture communication among nationalities is the deep communication, which is significant for the prevention of national culture's conflict, the integration of national culture and relationship among nationalities. The interaction of teenagers' culture in eastern and western regions promotes the national culture greatly and plays a positive part in the education of national culture identity.

\section{The Suggestions to Strengthen the Teenagers Cultural Exchange in the Eastern and Western Regions}

\subsection{Adopt Two-way Exchange Mode.}

At present, cultural exchange among teenagers in eastern and western regions are mainly in the form of unilateral communication, such as Plan of College Students' Volunteering to Serve in Western Regions and the establishment of minor nationalities colleges. Although the form of communication played a positive role in the east and west cultural exchanges between young people, this unilateral exchange has its limitations. For example, by taking part in the Plan of Serving West, volunteers can adopt many approaches to spread ideas and culture in the east to students in west regions in voluntary activities. However, teenagers in west can't have personal experience of the development and changes in east, nor can they deepen understanding of culture in eastern regions.

By adopting the mode of two-way communication,every university and school could create the short term communication project between the East and West areas. The teenagers of East and West areas could contact each other under the school's organization by the mode of "one-to-one", who could develop the preliminary understanding with each other. On this basis, both of them could have communication and exchange during the term. Although the time of this exchange is short, they can establish a long-term contact afterwards. Through these short term interactive activities like going to local schools to learn, the teenagers in eastern and western areas can develop friendship and connection with each other in the long term. When they go deep into local life, they can pick up all aspects of folk tradition and customs. Besides, in experiencing different cultural atmosphere and finding their similarities, they can comprehend the ethnic unity and harmony deeply.

\subsection{Increase Short-term Exchange Programs and Expand the Participant Scope of Exchange.}

At present, teenager cultural exchange activities between east and west areas generally last for one to three years, which belongs to long-term projects. And other forms of short-term projects such as experiential learning, exchange students are relatively small. In addition, participants at this stage exchange program are mostly university graduates or graduate students, and there are few projects for primary school and high school students. The coverage of the exchange projects is narrower.

Therefore, it is proposed that we should increase short-term exchange programs, exchange coverage should be extended to primary school and secondary school students in the form of study tours, exchange students project and other forms of communication. It will facilitate the teenagers' integration into the local environment, access to the customs and mutual understanding. At the same time, flexibility in the time of short-term exchange makes the scope of the project subject wider to get better results and achieve the purpose of ethnic unity and progress education. 


\subsection{Make Full Use of Traditional Media on Campus and New Media to Provide a Broader Platform for Cultural Exchanges between Teenagers in East and West Regions.}

At present, with the further development and popularization of the Internet, the emergence of a variety of media has changed our lives and young people get access to more information from diversified channels. In today's highly information-packed, multi- media society, mass media, an important means for the spread and development of traditional Chinese culture, plays an irreplaceable role in adolescent traditional culture education. Campus media has its unique advantages and is characterized by wide coverage and easy availability. Special column in campus broadcast, campus radio station, campus newspaper needs to be established to publicize the CPC and national policies, guidelines and the latest trends of nationalities. learning A platform of national unity and progress should thus be built to permeate education to students' daily life. New media, with its interactive and innovative features, is easily accessible to young people, attracting the attention of most of the young people. Therefore, we should broaden the channels of information through new media, such as the establishment of WeChat Platform, QQ Group, microblogging platform to send information to young people timely and effectively with a view to improving the education of ethnic unity and progress.

\subsection{Enhance the Government Policy Support.}

As a long-term and complicated social engineering project, education of ethnic unity and progress must under legal and policy protection. Since the carrying on of Reform and Opening up policy, China has made great achievements in democratic and legal construction. Ethnic legal system has been built with Constitution as the basis and ethnic regional autonomy laws as the fundamental law. But in general, China ethnic law construction still relatively lags behind. To further improve ethnic unity progress education, efforts should be made in two aspects. Firstly, abide by the present laws and regulations and provide legal protection for youth culture between east and west. Secondly, make new scientific and targeted special offers and policies to strengthen support for youth and cultural exchanges between east and west.

\subsection{Government, Charity Organizations and Social Organizations Provide Financial Support and Help the Implementation.}

Ethnic unity and progress education is not only the responsibility of the government, instead, the smooth development of adolescents from Eastern and western regions is everyone's duty. In recent years, private charities and social organizations of Chinese social welfare charity made outstanding contributions to China's charity cause. In 1985, the older Christians in China, such as bishop Ding Guangxun, Han Wenzao, established the Amity Foundation. Over the past 30 years, Amity Foundation has collected donation of more than 20 billion yuan and applied local government matching funds of more than 10 billion. Up to now, it has established the public welfare projects covering 31 provinces, cities and autonomous regions and more than tens of millions of poor people from over 200 counties, cities, districts benefited from it.

Ethnic unity and progress education needs financial support and organizational implementation from the government, charity institutions and social organizations. The government should encourage charity institutions and social organizations to provide funds and implement the relevant policies and regulations for East and West Area Youth Cultural Exchange Programs. Furthermore, efforts should be made to encourage more people to participate in it.

\subsection{Strenghen the Training of Teachers for the Education of Ethnic Unity and Progress.}

Just as the saying goes that "Education is the basic of a One-Hundred Year Strategy of a Nation. Good teachers guarantee a good education," teachers play an important role in the young people's learning process, and they can guide the young people's growth. Therefore, two measures should be taken: on the one hand, strengthen the training of teachers. Each school carries out targeted training according to the actual situation, such as listening to lectures, giving open class, learning experience communication, to strengthen the teachers' understanding of ethnic unity and progress education, further enhancing teachers' ideological quality. On the other hand, give targeted planning of teachers' recruitment and development. Colleges and colleges should enroll minority teachers who are 
enthusiastic and capable. In this way, the teenagers can get easy access to the minority culture in school life, which lay the foundation for the East and West cultural exchanges between young people.

\section{Conclusion}

Ethnic unity and progress education is a long-term task aiming at nation's stability. Organizing cultural exchange activities such as adopting the two-way communication, increasing the number of short-term exchange programs, expanding the scope of the participants in communication, has a positive effect on strengthening education on ethnic unity and progress.

\section{Acknowledgements}

The paper is funded by the following projects: 2014 China's Shandong Province Social Sciences Planning Projects -- Youth Research Fund (Shandong Province Youth Research Base Funded Project, No. 14CQSJ04); 2015 Training Plan to Innovation and Enterprise of Shandong Youth University of Political Science University Students.

\section{References}

[1] Yin Haiyan, Han Lijun, On the Theories of Creating Ethnic Unity and Progress in the New Era [J], Guangxi Ethnic Studies, 2015 (2)

[2] Li Ping, The Effectiveness of Ethnic Unity and Progress Education in Colleges and Universities [J], Journal of Liaoning Institute of Socialism, 2014 (9)

[3] Zhang Pingfen, Promote the Concept Innovation and Ethnic Progress in the Northwest Regions---From the Cultural Innovation Perspective [J], Journal of Chongqing University of Science and Technology (SOCIAL SCIENCE EDITION), 2012 (3)

[4] Liang Weihao, On the Development of China's Harmonious Ethnic relations [D], Jilin University Press, 2009

[5] Xi Jinping, The Speech on Conference Concerning Xinjiang Management Strategies: Adopting a Long-term Strategy and Laying a Solid Foundation Aiming at a Perpetual Safety and a Long Term Cause [N], The People's Daily, May, 30, 2014. 